\title{
El IDioma Chino, \\ LENGUA DEl Futuro
}

CPC Zelma Wong Torres

Directora del Centro de Extensión y Proyección Social - FCC.

\begin{abstract}
RESUMEN
China tiene un destacado lugar en la historia del libro, debido a que tempranamente creó un sistema de escritura y aportó grandes inventos, tales como el papel, la impresión con planchas móviles y la tinta. También es muy importante tener presente que para los chinos es primordial el amor a la tradicıón por ello su homogeneidad cultural ha sido más prolongada que la de ningún otro pueblo, lo que ha propiciado que su escritura sea la más antigua y que haya variado muy poco.

El nacimiento de la escritura siguió un camino similar al de otros pueblos que quisieron superar las limitaciones temporales y locales del mensaje oral. Utilizaron tarjas, palos con muescas, para dar fe a contratos privados y cuerdas con nudos para recordar asuntos comunitarios.

El presunto creador de la escritura China ha sido Cangjie y una leyenda que atribuye la invención de los ideogramas y su sistematización a Wang Xiezhi (317-420 a. C.), quien llegó a ser consıderado como el rey de la caligrafía China.

De todas formas el idioma chino es fácil, porque es una lengua monosilábica.
\end{abstract}

Palabras clave: Desarrollo, despegue, comercio exterior, base económica, tecnología.

\section{INTRODUCCIÓN}

Para nadie es desconocido lo que actualmente está sucediendo con China, cuya economía está despegando de forma alarmante, proyectándose en menos tiempo de lo previsto, en la que tendremos a la misma como primera potencia económica.

Como quiera que no debemos descuidar este despegue y considerando que muchos países están en vías de comercializar con China, es necesario que el Perú, prevea los mecanismos para también insertarnos en ese desarrollo.

\section{LA ESCRITURA CHINA}

La escritura china guarda de alguna ma-zra relación con esas rudimentarias inscripcones neolíticas de hace 5000 años.
Cangjie creó caracteres de acuerdo con los fenómenos naturales, tales como, las cambiantes formas del sol, la luna y las estrellas o en las huellas que dejaban los pájaros y animales sobre la arena, estos caracteres rudimentarios se transformarían a lo largo de diversas dinastías en los complejos ideogramas actuales.

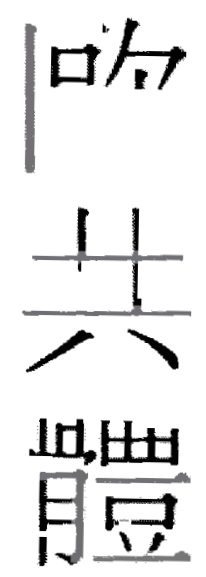


Hasta 221 años a.C., estando en el poder el emperador Qin Shi Huang, China tenía 7 modelos de escritura, las cuales dividían el país y eran ininteligibles unos en otros.

Este monarca fue vital para el desarrollo de un modelo de escritura llamado Xiaozhuan (letras pequeñas) que estandarizaba los trazos y sentaba las bases para la formación cuadricular de los caracteres chinos, ésta daría lugar, décadas después, a un modelo simple conocido como Lishu, que era utilizado por la gente del pueblo, también conocido como "escritura en cárcel" porque se dice que fue creado por un prisionero llamado Cheng Miao.

La escritura Lishu fue popularizada por la dinastía Han 206 a. C - 220 d. C, su trazo simple y regular dio paso a los caracteres modernos. A finales de esta dinastía apareció una escritura de líneas rectas y formas cuadradas llamada Kaishu que es en gran medida el modelo estándar de la escritura China actual.

\section{CARACTERES}

A los ojos occidentales, los caracteres chinos parecen indescifrables. Trazos menudos y artísticos que parecen las patas de cientos de insectos desplegados en columnas sobre una hoja de papel. Sin embargo, estos ideogramas están formados por cuatro modelos de caracteres: los jeroglíficos, los indicativos, los asociativos y los compuestos fonéticos.

Para entender éstos, existen algunos ejemplos elementales: si a la izquierda del jeroglífico "cuchillo" se le agrega una tilde, se forma la palabra "filo de cuchillo" (carácter indicativo); la palabra "comparar" está formada por dos líneas que representan a dos personas midiéndose hombro a hombro (compuesto asociativo); o un ideograma raíz como "madera" puede formar muchas palabras, como “árbol”, “tabla”, “forestal”, “ramo", “sauce”, etc., si se le agregan tildes u otros pictogramas (a estos se les llamaba compuestos fonéticos).

Incluso existen otras asociaciones que dicen mucho de la sabiduría china, los trazos que representan a un hombre con los brazos extendidos significan "grande" y la palabra "bueno" se compone de los caracteres que significan "mujer" e "hijo". Después existen combinaciones de radicales fonéticos y semánticos, como la palabra "río" formada del radical agua y el fonema "ke".

Actualmente existen 3000 caracteres básicos de dominio de la lengua china. Pero antes han aparecido diccionarios completos que han recogido entre cincuenta mil caracteres, aunque la mayoría de ellos están hoy en desuso.

Desde la década del sesenta, veintiséis letras del alfabeto latino son utilizadas oficialmente para traducir la fonética china, y son usadas generalmente en documentos oficiales ante la ONU y organismos internacionales para designar los nombres de personas y ciudades.

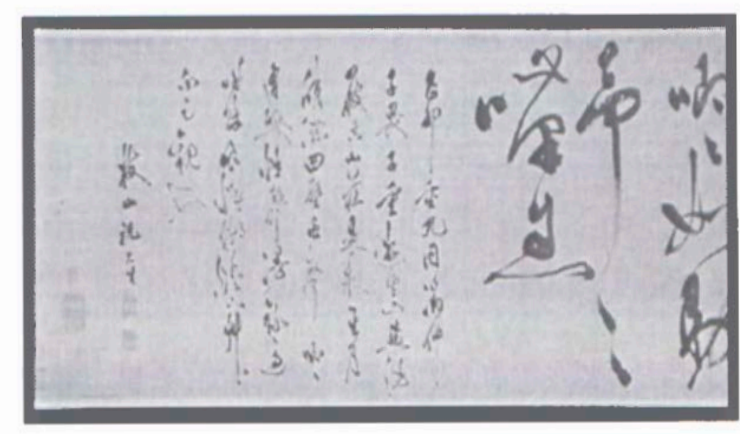

Cuatro mil quinientos caracteres son necesarios para leer un periódico en ese idioma, y de éstos unos dos mil dialectos, (más de cincuenta y cinco idiomas) y cuatrocientos sílabas, que están formadas por veintiún sonidos iniciales y treinta y siete sonidos finales. Todos estos números encuentran cohesión en la escritura, pues aunque de una 
provincia a otra los ciudadanos no se entiendan al hablar, la caligrafía china, sea cual sea su lugar de origen, es universal.

En 1958, Mao Zedong implantó como idioma oficial de China el "mandarín" o "Putonghua", lengua originaria de Pekín que es hablada actualmente por el $75 \%$ de la población.

Es así que se puso en práctica un alfabeto romanizado de 58 símbolos; el uso del Pinyin o trascripción fonética en caracteres latinos, que facilita la escritura; la misma que dejaría de escribirse exclusivamente de manera vertical y de derecha a izquierda, adaptándose al estilo occidental: de izquierda a derecha y de forma horizontal.

Pese a toda reforma, los caracteres permanecieron sin cambios hasta el año 1964, que se produjo la simplificación luego de la Constitución de la República Popular, en que cambiaron su forma unos 2000 caracteres, con la intención de facilitar su aprendizaje a futuras generaciones.

Dependiendo de la entonación y sonido que se utiliza en una palabra, para decirla en chino, puede significar hasta cinco cosas diferentes.

\section{LOS BYTES}

La última revolución en la historia ha ıdo la inclusión del chino en el "Dian Mao", cerebro electrónico o computadora. A través de programas de software especiales se han podido condensar en las décadas este univerco de caracteres en un teclado.

Hoy en China, el correo electrónico ha :eemplazado a los pinceles y el papel, que es ruo invento chino de hace catorce siglos.

Una encuesta publicada en la capital de China revela, precisamente, que el $67 \%$ de ws chinos está olvidando como escribir cier- tos ideogramas por el uso cotidiano de la computadora, y que sólo un $21 \%$ utiliza la caligrafía, frente a un $12 \%$ que ya rara vez escribe un manuscrito.

Para contrarrestar esto, las escuelas están reforzando sus cursos de caligrafía con pinceles, algo que los chinos han asumido como un arte desde tiempo inmemorables.

Li Po, uno de los más grandes poetas de la dinastía Tang (618-1 279 d. C.), decía que cuando escribía intimidaba a la luna y la lluvia, pues estaba convencido de que esta escritura fina y elegante era, después de todo de todo, el reflejo del alma.

\section{CONCLUSIÓN}

¿Por qué aprender el idioma chino?

En China se controlaba el comercio exterior mediante un sistema económico planificado (dirigido), el $1^{\circ}$ de julio del presente año ha sido un día histórico para los empresarios chinos, pues desde ese día comenzó a desarticularse el sistema económico planificado. A partir de esa fecha, cualquier empresario chino puede comercializar libremente con cualquier otro país extranjero sin intervención del gobierno.

Por medio de esta nueva ley de aprobación administrativa, se retira el dominio de los gobiernos locales, provinciales, nacionales, de todas las resoluciones administrativas, suprimiendo más de dos mil normas y permisos que entorpecían el desarrollo empresarial chino, éste es un gran golpe para la economía centralista china.

Consultando a Wen Jiabao, por el Consejo de Estado Chino, dijo que "este cambio hará que el mercado juegue un papel fundamental en la distribución de normas" con ello estaba validando a Adam Smith, padre teórico del capitalismo, quien hace 200 años se 
refería a la "mano invisible" que regulaba y distribuía los recursos de la sociedad.

Luego de 55 años de economía centralizada y a casi 30 años del comienzo de la reforma iniciada por Deng Siaoping, las fuerzas del mercado, por primera vez, comienzan a sentir pasos del coloso asiático cautelado por Beijing. Ahora los peruanos debemos preguntarnos cómo China va a manejar la amplia base económica, porque sigue presente la superestructura política del país socialista.

Hablar de China hoy en día, es hablar de economía mundial. Los analistas provistos de un lenguaje místico, aluden a un milagro. El "Made in China" fue puesto de moda, no sólo en Perú sino en todo el mundo.

China es poderosa importando prendas de vestir, juguetes, calzados y manufacturas de cuero. También lo es ensamblando pro- ductos con valor tecnológico. La llamada fábrica del mundo es un eslabón fundamental en la cadena de abastecimiento de las multinacionales, y en todos los rubros.

De lo expuesto se aprecia que tenemos un material importante para los profesionales investigadores que contemplan un país que cincuenta y cinco años atrás tenía la misma economía que la peruana, y ahora se está convirtiendo en un país superpotente, un gran reto para los profesionales es el de despejar la incógnita política y económica de China.

\section{REFERENCIAS}

Asociación Peruano China

Boletín Informativo No 23

Setiembre 2004-11-02

http://www.spanish.xinhuanet.com/iber.htm 